\title{
PENGARUH AKUNTANSI ZAKAT TERHADAP AKUNTABILITAS PUBLIK (Studi Kasus Di Badan Amil Zakat Nasional (BAZNAS) dan Lembaga Amil Zakat (LAZ) Kabupaten/Kota Provinsi Sumatera Selatan)
}

\author{
${ }^{1}$ Bayu Dharmaraga Alkahfi, ${ }^{2}$ Taufiq Taufiq, ${ }^{3}$ Inten Meutia \\ ${ }^{123}$ Universitas Sriwijaya J1. Srijaya Negara, Bukit Lama, Kec. Ilir Bar. I, Kota Palembang \\ bayudharma17@gmail.com
}

\begin{abstract}
Abstrak
Tujuan dari penelitian ini adalah untuk mengetahui pengaruh akuntansi zakat terhadap akuntabilitas publik BAZNAS dan LAZ yang berada di Provinsi Sumatera Selatan dengan metodologi yang digunakan adalah deskriptif menggunakan kuisioner. Sedangkan analisis data yang digunakan adalah analisis regresi linear sederhana. Sehingga dari kajian ini dapat diketahui bahwa akuntansi zakat berpengaruh terhadap akuntabilitas BAZNAS dan LAZ di Provinsi Sumatera Selatan sebesar 73,9\%, kemudian berdasarkan hasil kajian diketahui kecenderungan akuntansi zakat yang dilaksanakan oleh lembaga zakat di Provinsi Sumatera Selatan memiliki kriteria kurang baik sebanyak 3 lembaga atau 10\%, 2 lembaga kriteria cukup baik, 5 lembaga dengan kriteria baik dan dengan kriteria sangat baik sebesar 66,6\% atau sebanyak 20 lembaga amil zakat.
\end{abstract}

Kata Kunci : Akuntansi Zakat, Akuntabilitas Publik, Lembaga Amil Zakat

\begin{abstract}
The purpose of this study was to determine the effect of zakat accounting on public accountability of BAZNAS and LAZ in South Sumatra Province with the methodology used was descriptive using a questionnaire. While the data analysis used is simple linear regression analysis. So from this study it can be seen that the accounting for zakat influences the accountability of BAZNAS and LAZ in South Sumatra Province by $73.9 \%$, then based on the results of the study it is known that the tendency of zakat accounting carried out by zakat institutions in South Sumatra Province has unfavorable criteria of 3 institutions or 10\%, 2 institutions are quite good criteria, 5 institutions with good criteria and with very good criteria are $66.6 \%$ or as many as 20 amil zakat institutions.
\end{abstract}

Keywords: Zakat Accounting, Public Accountability, Amil Zakat Institutions

\section{Pendahuluan}

Provinsi Sumatera Selatan merupakan provinsi terluas di pulau Sumatera, yang luasnya mencapai $91.592,43 \mathrm{~km}^{2}$. Luas wilayah yang besar berbanding lurus dengan banyaknya jumlah penduduk, setidaknya terdapat 8.506.239 jiwa penduduk yang tersebar pada tujuh belas kabupaten kota di Provinsi Sumatera Selatan. Penduduk Sumatera Selatan mayoritas menganut agama Islam, berdasarkan data Badan Pusat Statistik (2018) menerangkan sebesar 96,25\% penduduk Sumatera Selatan adalah muslim atau sebanyak 8.188.045 jiwa menganut agama Islam. 


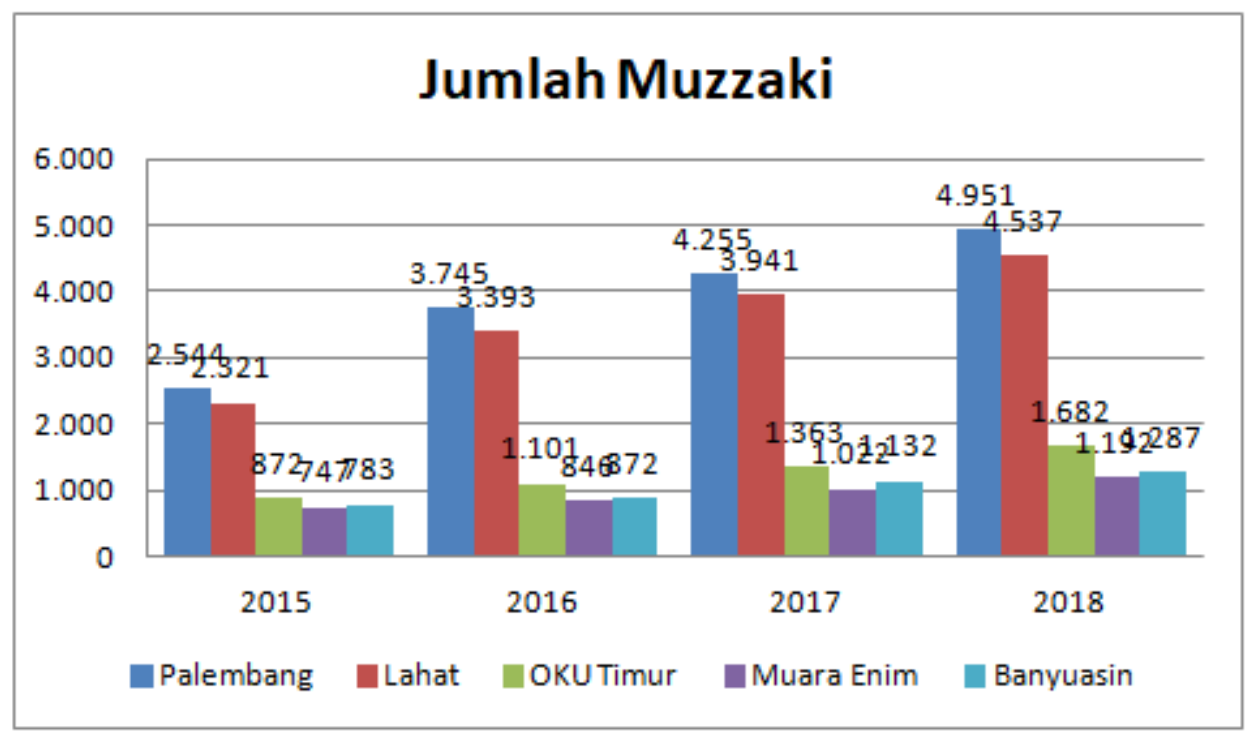

Sumber : Basnaz Provinsi Sumatera Selatan

\section{Gambar 1.1. Jumlah Muzzaki Provinsi Sumatera Selatan}

Lahat 2.321 orang, OKU Timur, Muara

Besarnya jumlah penduduk muslim membuat potensi perkembangan ekonomi Islam menjanjikan di Sumatera Selatan, selain tumbuh suburnya bank-bank syariah non riba, potensi zakat di Sumatera Selatan juga sangat menjanjikan. Dilansir dari laman sumsel.tribunnews.com (Maret 7, 2017) potensi zakat provinsi Sumatera Selatan mencapai 2,3 triliun rupiah. Meski memiliki potensi zakat yang besar, menurut Forum Zakat Wilayah (Fozwil) Sumatera Selatan pencapaian total zakat hanya sekitar 50 miliar rupiah atau hanya $2 \%$ dari potensi zakat.

Jumlah penduduk muslim yang besar di Provinsi Sumatera Selatan berbanding lurus dengan jumlah muzzaki yang menunaikan zakat, setidaknya terdapat 2.544 orang di Kota Palembang,
Enim dan Musi Banyuasin masing 872, 747 orang dan 783 orang yang terdaftar sebagai muzzaki pada tahun 2015. Jumlah muzzaki ini setiap tahunnya terus mengalami trend meningkat, dapat dilihat pada gambar $1.1 \mathrm{di}$ atas bahwa pada tahun 2017 jumlah muzzaki mengalami peningkatan baik di Kota Palembang, Lahat maupun Muara Enim, dimana mengalami peningkatan sebesar $13,61 \%$ atau sebesar 510 orang untuk Kota Palembang, 548 orang Kabupaten Lahat dan 176 orang untuk Muara Enim atau sebesar 20,8\%. Peningkatan jumlah muzzaki juga kembali terjadi pada tahun 2019 untuk Kota Palembang sendiri mengalami peningkatan sebanyak 696 orang dari tahun 2018 ke 2019 atau sebanyak 16,35\%, hal ini menurut Alkahfi dipengaruhi faktor semakin sadarnya umat muslim akan 
pentingnya menunaikan zakat (Alkahfi, 2018).

Pada tahun 2017 Baznas Sumsel melalui laman republik.co.id menerangkan bahwa terdapat lima daerah penghimpun dana zakat terbesar di Sumatera Selatan, yaitu Kota Prabumulih sebesar Rp 3,2 miliar, Kabupaten Lahat Rp 3,072 miliar disusul oleh OKU Timur, Pagar Alam, dan Palembang dengan nilai zakat $\operatorname{Rp} 1,8$ miliar, Rp 1,6 miliar dan Rp 1,3 miliar (republika.co.id april 3, 2017). Potensi zakat yang besar Baznas Sumsel melalui Baznas kabupaten kota pun sering kali mendapat penghargaan, contohnya pada tahun 2016 Baznas Kota Prabumulih meraih rekor muri dari Museum Rekor Indonesia untuk pembangunan 337 unit rumah baru bagi warga fakir dan miskin melalui dana zakat dan infaq tanpa Dana APBD Kota Prabumulih (tribunnews.com), selain itu terdapat juga program Sumsel cerdas, Sumsel peduli, Sumsel sehat, Sumsel taqwa dan Sumsel makmur dari Baznas Provinsi Sumatera Selatan (Alkahfi, 2018). Tidak hanya Baznas Lembaga Amil Zakat (LAZ) lainnya pun memiliki kontribusi yang luar biasa dalam pembangunan di bidang ekonomi, pendidikan maupun sosial, seperti program beasiswa, pembangunan puskesmas oleh dompet duafa (sumselupdate.com). Besarnya manfaat zakat sudah selayaknya pemerintah melalui Baznas maupun LAZ di Provinsi Sumatera Selatan lebih serius dalam mengelolah dana zakat. Potensi zakat di Sumatera Selatan yang mencapai Rp 3,2 triliun seharusnya dapat dimaksimalkan agar tujuan mulia zakat dapat terpenuhi, yaitu peretasan kemiskinan (Abdullah, Mat Derus, \& Al-Malkawi, 2015).

Badan Amil Zakat Nasional adalah badan resmi yang dibentuk pemerintah berdasarkan Keputusan Presiden RI nomor 08 Tahun 2001 untuk menghimpun dan menyalurkan dana zakat baik tingkat nasional, provinsi dan kota (baznas.go.id). Berdasarkan Undang-undang Nomor 23 Tahun 2011 tentang Pengelolan Zakat dan didukung Peraturan Pemerintah Nomor 14 Tahun 2014 menerangkan bahwa dalam pengumpulan, pendistribusian, dan pendayagunaan zakat Baznas dibantu oleh lembaga amil zakat (LAZ) dan saling terintegrasi satu sama lain.

Sebagai badan yang mengelola dana publik sudah selayaknya Baznas dan lembaga zakat memiliki tuntutan untuk mewujudkan akuntabilitas. Akuntabilitas adalah hubungan antara agen untuk menunjukkan kinerja kepada pihak yang memberikan amanah (Akbar, Pilcher, \& Perrin, 2012), sedangkan menurut Hughes akuntabilitas ialah mereka yang bertindak atas nama orang atau kelompok lain, melaporkan kembali kepada orang atau 
kelompok itu, atau bertanggung jawab kepada mereka dengan cara tertentu (Hughes, 2003).

Dana zakat yang dikelola Baznas dan lembaga zakat merupakan dana umat, oleh sebab itu yang dibutuhkan lebih dari akuntablitas biasa, yaitu akuntabilitas publik. Menurut Mardiasmo akuntabilitas publik adalah suatu kewajiban dari pemegang amanah (agent) untuk mempertanggung-jawabkan, melaporkan dan menyajikan serta mengungkapkan semua kegiatan yang dilakukannya kepada pihak yang memberikan amanah (principal) dan secara langsung maupun tidak langsung memiliki hak serta kewenangan untuk meminta pertanggungjawaban (Mardiasmo, 2004). Sedangkan menurut Yusrianti dan Safitri akuntabilitas publik adalah perwujudan kewajiban unit organisasi atau seseorang memberikan informasi atas kinerja pemerintah kepada pihak yang berkepentingan (Yusrianti \& Safitri, 2015)

Berdasarkan survei Public Interest Research and Advocacy Centre (PIRAC) pada tahun 2007 menjelaskan penyebab utama terjadinya penurunan jumlah penyaluran zakat dari muzakki ke lembaga zakat disebabkan oleh ketidakpercayaan muzakki (PIRAC, 2007), sedangkan menurut Rahman faktor lain yang menjadi penyebab penurunan penerimaan zakat adalah rendahnya kesadaran masyakarat yang belum memahami kewajiban zakat dan kurang kerpercayaan (trust) muzakki terhadap amil serta kebiasaan membayar zakat secara langsung, namun yang terpenting yaitu kepercayaan, jika muzakki telah mempercayai amil, sosialisasi tentang kewajiban zakat akan mempermudah masyarakat memahami kewajiban berzakat dan akan menarik muzakki membayar zakat melalui badan amil (Rahman, 2015).

Mendapatkan kepercayaan dari muzzaki adalah hal yang sangat penting dilakukan oleh lembaga zakat. Menurut Adnan lembaga zakat harus memberikan kepercayaan dengan cara menjauhkan diri dari tindakan kejahatan korupsi seiring dengan memastikan transparansi dalam pengelolaan zakat (Adnan, 2015). Transparasi pengelolaan menurut Hidayat, Rohaeni dan Zanatun dapat dicapai dengan pelaporan yang baik sesuai dengan PSAK No. 109 Tahun 2010, sehingga PSAK 109 menjadi point penting dalam perkembangan transparansi pelaporan keuangan lembaga zakat (Hidayat, Rohaeni, \& Zanatun, 2018). Selain itu sistem akuntansi yang sesuai dengan PSAK 109 akan menjadi faktor peningkat kepercayaan muzzaki dalam pengelolaan zakat sebagai pemberdayaan ekonomi umat Islam, sehingga penyaluran zakat yang efektif dan tepat guna, akan dapat terwujud (Roziq, 2017).

Kenyataanya lembaga amil zakat telah melaksanakan akuntansi zakat, namun 
Bayu Dharmaraga Alkahfi, Taufiq Taufiq, Inten Meutia, Pengaruh Akuntansi Zakat

belum sepenuhnya sesuai dengan PSAK Nomor 109. Contohnya pada Lazisnu Kabupaten Kudus maupun Baznas Kota Bitung yang dalam pelaporan akuntansinya hanya mengacu pada kebutuhan dan arahan atasan (Elvinda, 2016), kemudian hasil penelitian Roziq menemukan bahwa dari lima lembaga zakat di Kabupaten Jember hanya ada satu lembaga yang menerapkan PSAK Nomor 109 (Roziq, 2017). Untuk menumbuhkan motivasi dalam menyusun laporan akuntansi yang sesuai PSAK Nomor 109 penulis akan melihat pengaruh akuntansi zakat terhadap akuntabilitas publik lembaga zakat, yang nantinya akan berbanding lurus dengan kepercayaan muzzaki terhadap lembaga zakat, sehingga pengumpulan dana zakat dapat di optimalkan.

Berdasarkan uraian di atas, penulis tertarik untuk meneliti mengenai "Pengaruh Akuntansi Zakat terhadap Akuntabilitas Publik Badan Amil Zakat Nasional (Baznas) dan Lembaga Amil Zakat (LAZ) di Provinsi Sumatera Selatan”.

\section{Pembahasan}

\section{A. Landasan Teori}

Akuntansi zakat ialah proses recognition atau pengakuan kepemilikan serta meansurement berupa pengukuran nilai kekayaan yang dimiliki oleh muzakki guna menentukan nisab zakat kekayaan muzakki dalam rangka perhitungan zakat yang bersangkutan (Mursyidi, 2003). Sedangkan menurut Adnan Akuntansi Zakat adalah pencatatan dan penyajian pengumpulan dan pendistribusian dana zakat sesuai dengan PSAK Nomor 109 (Adnan, 2015). PSAK Nomor 109 tentang akuntansi zakat dan infaq / sedekah bertujuan untuk mengatur pengakuan, pengukuran, penyajian dan pengungkapan transaksi zakat dan infaq/sedekah (Ikatan Akuntan Indonesia, 2008).

Akuntabilitas atau dalam bahasa inggris accountability, secara harfiah diartikan dapat dipertanggungjawabkan dalam kata sifat disebut accountable. Akuntabilitas adalah hubungan antara agen untuk menunjukkan kinerja kepada pihak yang memberikan amanah (Akbar et al., 2012). Menurut Ramdhani akuntabilitas adalah tanggungjawab dari amanah yang melekat pada suatu lembaga (Keutamaan, Dan, \& Publik, 2018), sedangkan menurut Hughes akuntabilitas ialah mereka yang bertindak atas nama orang atau kelompok lain, melaporkan kembali kepada orang atau kelompok itu, atau bertanggung jawab kepada mereka dengan cara tertentu (Hughes, 2003).

Mardiasmo, Turner and Hulme menjelaskan bahwa akuntabilitas terdiri dari dua jenis, yaitu akuntabilitas vertikal dan akuntabilitas horizontal (Mardiasmo, 2004; Turner \& Hulme, 1997), Menurut 
Meutia akuntabilitas horizontal merupakan akuntabilitas yang diberikan kepada tiga pihak yaitu direct stakeholders, indirect stakeholders dan alam, sedangkan akuntabilitas vertikal ialah akuntabilitas yang ditujukan hanya kepada Allah SWT (Meutia, 2010).

Menurut Mahmudi dan Rasul Akuntabilitas Publik terdiri atas beberapa aspek dimensi yang harus dipenuhi oleh organisasi-organisasi sektor publik antara lain akuntabilitas hukum dan kejujuran (accountability for probity and legality), akuntabilitas manajerial (managerial accountability), akuntansi program (program accountability), Akuntabilitas kebijakan (policy accountability) dan Akuntabilitas finansial (financial accountability) (Mahmudi, 2013; Rasul, 2003).

Penelitian ini adalah pengembangan dari penelitian-penelitian terdahulu, dengan maksud untuk memberikan bukti empiris mengenai pengaruh akuntansi zakat terhadap akuntabilitas publik lembaga amil zakat. Berdasarkan uraian sebelumnya dan penelitian-penelitian terdahulu, maka kerangka pemikiran dalam penelitian ini adalah sebagai berikut :

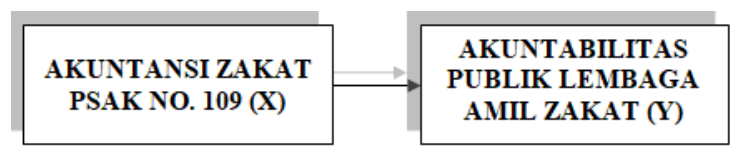

Gambar 2.1. Kerangka Pemikiran

\section{B. Metode Penelitian}

Penelitian ini termasuk jenis penelitian kuantitatif, karena melalui sebuah proses yang membangun hipotesis dan menguji secara empirik hipotesis yang dibangun (Ferdinand, 2014). Jenis data yang digunakan adalah data primer, data primer merupakan data penelitian yang diperoleh secara langsung dari sumber asli.

Populasi sasaran dalam penelitian ini adalah 18 Baznas Kabupaten/Kota dan Lembaga Amil Zakat (LAZ) yang berada di Provinsi Sumatera Selatan. Keseluruhan Baznas Kabupaten/Kota dan Lembaga Amil Zakat tersebut menjadi sampel dalam penelitian ini (sampel jenuh).

Pada penelitian ini peneliti menggunakan data kualitatif yang diukur menggunakan instrumen kuesioner. Metode yang digunakan dalam penelitian ini adalah metode semantik diferensial dengan skala data interval.

Data yang digunakan dalam penelitian ini adalah data primer. Pada penelitian ini penulis menggunakan teknik Penelitian Lapangan atau Field Research. Penelitian lapangan adalah teknik memperoleh data primer dengan cara bertemu secara langsung dan melibatkan pihak responden yang dijadikan sampel dalam penelitian.

Uji hipotesis yang digunakan pada penelitian ini adalah analisis regresi linier sederhana dengan cara meregres variabel 
Bayu Dharmaraga Alkahfi, Taufiq Taufiq, Inten Meutia, Pengaruh Akuntansi Zakat

independen terhadap variabel devenden. Hasil pengujian regresi sederhana akan menampilkan pengaruh antara variabel akuntansi zakat (X) terhadap variabel akuntabilitas publik (Y).

\begin{tabular}{|c|c|c|c|c|c|}
\hline 2 & 91 & - & 109 & 2 & 6,66 \\
\hline 3 & 110 & - & 128 & 1 & 3,33 \\
\hline 4 & 129 & - & 147 & 7 & 23,33 \\
\hline 5 & 148 & - & 166 & 14 & 46,66 \\
\hline 6 & 167 & - & 185 & 3 & 10,00 \\
\hline
\end{tabular}

Pada penelitian ini data diperoleh dengan mengirimkan secara langsung kuesioner serta melalui kuisioner online menggunakan google form kepada responden yang mewakili tiap lembaga amil zakat di kabupaten/kota pada Provinsi Sumatera Selatan. Dari 32 kuesioner yang disebarkan terdapat 2 kuisioner yang tidak kembali sehingga terdapat 30 kuisioner yang dapat dilanjutkan untuk dianalisis deskriptif dan regresi.

Instrumen yang digunakan untuk mengukur akuntansi zakat dengan kuisioner yang terdiri dari 20 pernyataan, yang tiap pernyataan memiliki nilai antara 1 sampai dengan 10 dengan skala interval. Nilai 1 mewakili pernyataan tidak pernah sedangkan nilai 10 mewakili pernyataan selalu dilakukan. Skor harapan terendah adalah 20 point sedangkan skor untuk harapan tertinggi adalah 200 point.

Adapun distribusi frekuensi dari hasil kuisioner yang disebar adalah sebagai berikut :

\section{Tabel 4.1. Distribusi Frekuensi Variabel} Akuntansi Zakat

\begin{tabular}{cccccc}
\hline No & \multicolumn{2}{c}{ Interval } & F & \% \\
\hline 1 & 72 & - & 90 & 3 & 10,00
\end{tabular}

Online ISSN : 2540-8402 | Print ISSN : 2540-8399

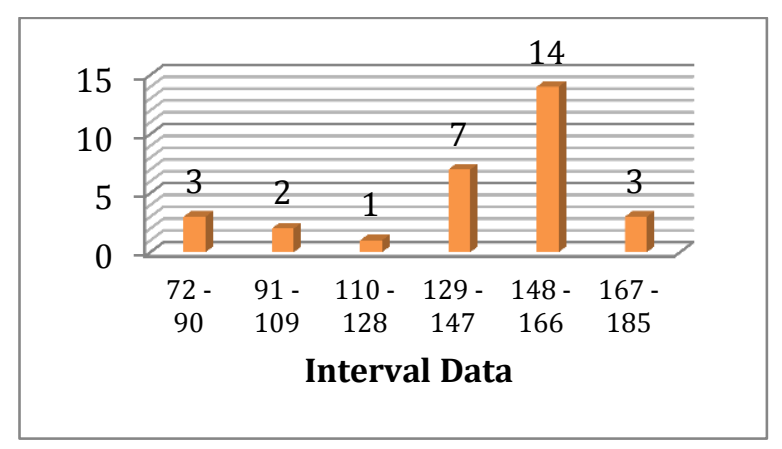

Gambar 4.1. Grafik Distribusi Frekuensi

\section{Variabel Akuntansi Zakat}

Pada table 4.1 dan gambar 4.1 di atas diketahui bahwa jumlah perolehan skor terendah diperoleh pada kelas interval keempat yaitu 110-128 dengan nilai sebesar $3,3 \%$, sedangkan perolehan skor paling banyak diperoleh pada kelas interval 148166 sebesar $46,67 \%$.

Kemudian peneliti menentukan kriteria kecenderungan variabel akuntansi zakat, dengan menghitung rata-rata ideal $\mathrm{Mi}=1 / 2$ (nilai tertinggi + nilai terendah $)$ yaitu $1 / 2(200+20)=110$ dan standar deviasi ideal $(\mathrm{SDi})=1 / 6$ (nilai tertinggi nilai terendah) yaitu 1/6 $(200-20)=30$. Berdasarkan perhitungan tersebut kriteria akuntansi zakat dapat dikategorikan kedalam 4 (empat) kriteria yaitu sangat baik $(\mathrm{X}>\mathrm{Mi}+\mathrm{SDi})$, baik $(\mathrm{Mi}<\mathrm{X}<\mathrm{Mi}+$ 
SDi), cukup baik $(\mathrm{Mi}-\mathrm{SDi}<\mathrm{X}<\mathrm{Mi})$, dan kurang baik $(\mathrm{X}<\mathrm{Mi}-\mathrm{SDi})$.

\section{Tabel 4.2. Distribusi Kategori Variabel}

Akuntansi Zakat

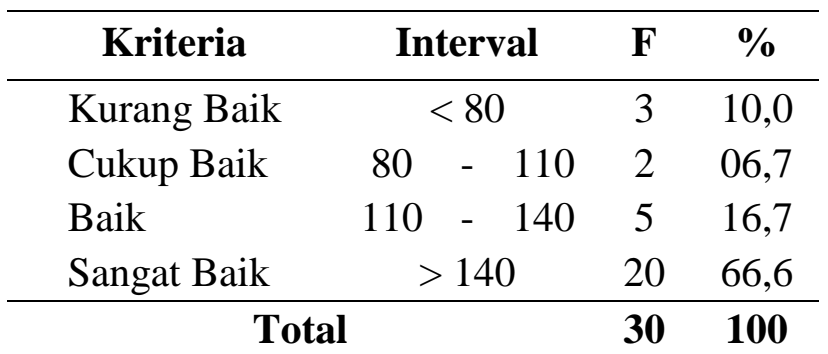

\section{Kriteria Variabel Akuntansi Zakat}

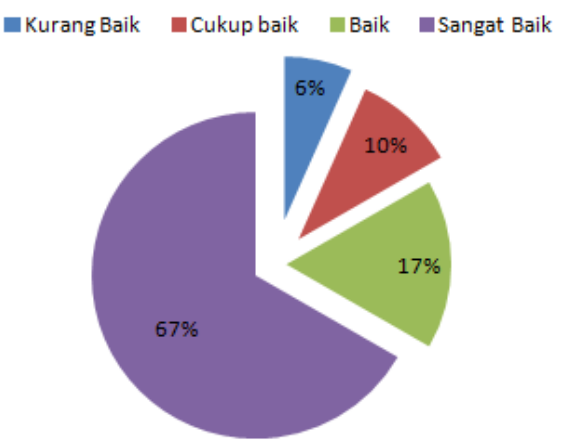

Gambar 4.2. Grafik Kriteria Variabel Akuntansi Zakat

Pada table 4.2 dan gambar 4.2 di atas menunjukkan adanya kecenderungan akuntansi zakat yang dilaksanakan oleh lembaga zakat memiliki kriteria sangat baik dengan jumlah sebanyak 20 lembaga zakat atau $67 \%$ kemudian $17 \%$ dengan kriteria tidak baik atau sebanyak 5 lembaga zakat. Selanjutnya untuk kriteria cukup baik dan kurang baik memiliki presentasi $16 \%$ dimana kriteria cukup baik sebesar $10 \%$ atau sebanyak 3 lembaga, kriteria kurang baik sebesar $6 \%$ atau 2 lembaga zakat.

Masih terdapatnya lembaga zakat dengan kriteria kurang baik disebabkan masih terdapat lembaga zakat yang belum menerapkan pencatatan yang sesuai dengan akuntansi zakat, contohnya pada PSAK No. 109 point 14 yang mewajibkan lembaga zakat membuat daftar mustahik penerima zakat yang ditentukan oleh muzaaki, masih ada amil yang belum memiliki bukti atau dokumen penunjang mustahik layak menerima zakat, kemudian point PSAK No. 109 point 35 yang mewajibkan lembaga zakat mengungkapkan hal-hal terkait zakat, seperti prioritas penyaluran zakat, kebijakan pembagian dana amil dan dana zakat, metode penetuan nilai wajar untuk zakat non kas, namun lembaga zakat masih banyak yang belum mengungkapkan kebijakan penyaluran prioritas.

\section{Akuntabilitas Publik}

Instrumen yang digunakan untuk mengukur akuntabilitas publik adalah kuisioner yang terdiri dari 16 pernyataan, yang tiap pernyataan memiliki nilai antara 1 sampai 10 dengan menggunakan skala interval. Nilai 1 mewakili pernyataan yang tidak pernah dilakukan sedangkan nilai 10 mewakili pernyataan yang selalu dilakukan. Skor harapan terendah adalah 16 point sedangkan skor untuk harapan tertinggi adalah 160 point.

Adapun distribusi frekuensi dari hasil kuisioner yang disebar adalah sebagai berikut : 
Tabel 4.3. Distribusi Frekuensi Variabel Akuntabilitas Publik

\begin{tabular}{|c|c|c|c|c|}
\hline No & \multicolumn{2}{|c|}{ interval } & $\mathbf{F}$ & $\%$ \\
\hline 1 & 65 & 79 & 3 & 10,00 \\
\hline 2 & 80 & 94 & 1 & 3,33 \\
\hline 3 & 95 & 109 & 2 & 6,66 \\
\hline 4 & 110 & - $\quad 124$ & 9 & 30,00 \\
\hline 5 & 125 & $\begin{array}{l}-\quad 139 \\
-\quad 1\end{array}$ & 13 & 43,33 \\
\hline 6 & 140 & $\begin{array}{l}-\quad 154 \\
\end{array}$ & 2 & 6,66 \\
\hline \multicolumn{3}{|c|}{ Jumlah } & 30 & 100,00 \\
\hline
\end{tabular}

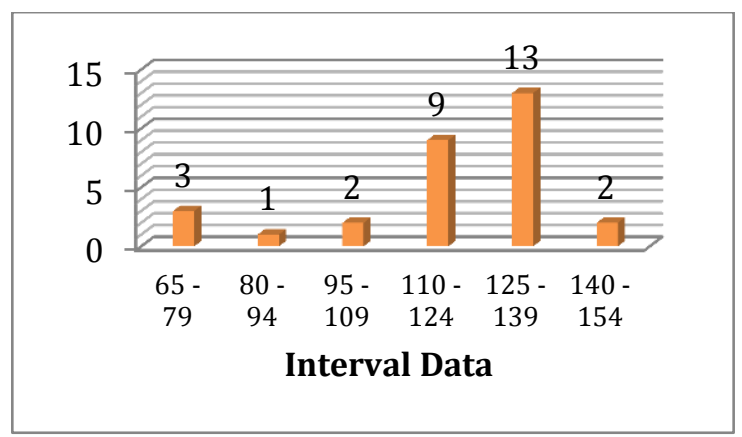

Gambar 4.3. Grafik Distribusi Frekuensi Variabel Akuntabilitas Publik

Pada table 4.3 dan gambar 4.3 di atas dapat diketahui bahwa frekuensi interval yang paling banyak diperoleh pada kelas interval kedua yaitu 125-139 sebanyak 13 lembaga zakat atau sebesar $43,3 \%$, sedangkan perolehan skor terendah diperoleh pada kelas interval kedua yaitu pada interval 80 - 94 sebesar 3,33\% atau sebesar 1 lembaga zakat.

Kemudian peneliti menentukan kriteria kecenderungan dari variabel akuntabilitas publik dengan menghitung rata-rata ideal $\mathrm{Mi}=1 / 2$ (nilai maksimal + nilai minimal) yaitu $1 / 2(160+16)=88$ dan standar deviasi ideal $(\mathrm{SDi})=1 / 6$ (nilai maksimal - nilai minimal) yaitu 1/6 (200 20) $=24$. Berdasarkan perhitungan tersebut kriteria akuntabilitas publik dapat dikategorikan kedalam 4 (empat) kriteria yaitu sangat baik $(\mathrm{X}>\mathrm{Mi}+\mathrm{SDi})$, baik $(\mathrm{Mi}$ $<\mathrm{X}<\mathrm{Mi}+\mathrm{SDi}$ ), cukup baik $(\mathrm{Mi}-\mathrm{SDi}<$ $\mathrm{X}<\mathrm{Mi})$, dan kurang baik $(\mathrm{X}<\mathrm{Mi}-\mathrm{SDi})$.

\section{Tabel 4.4. Distribusi Kategori Variabel} Akuntabilitas Publik

\begin{tabular}{|c|c|c|c|}
\hline Kriteria & Kriteria & $\mathbf{F}$ & $\%$ \\
\hline Kurang Baik & $<64$ & - & - \\
\hline Cukup Baik & $64-88$ & 4 & 13,4 \\
\hline Baik & $110-134$ & 3 & 10,0 \\
\hline Sangat Baik & $>134$ & 23 & 76,6 \\
\hline \multicolumn{2}{|c|}{ Total } & 30 & 100 \\
\hline
\end{tabular}

\section{Kriteria Variabel Akuntanbilitas Publik}

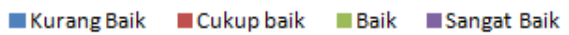

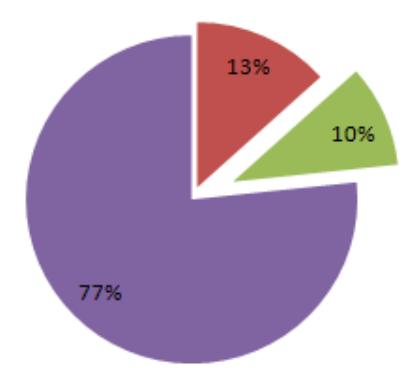

Gambar 4.4. Grafik Kriteria Variabel Akuntansi Zakat

Pada table 4.4 dan gambar 4.4 di atas menunjukkan adanya kecenderungan lembaga amil zakat menunjukkan akuntabilitas publik yang dilaksanakan memiliki kriteria cukup baik sebanyak 4 lembaga atau 16,4\% dan 3 lembaga dengan kriteria baik. Kemudian untuk kriteria 
sangat baik memiliki presentasi $76,6 \%$ atau sebanyak 23 lembaga amil zakat.

Kriteria akuntabilitas publik yang diterapkan oleh lembaga zakat di provinsi Sumatera Selatan menunjukkan kriteria kecenderungan sangat baik, hal ini menjelaskan bahwa sebanyak 23 lembaga atau $76,6 \%$ lembaga zakat telah melaksanakan kegiatan pengumpulan zakat dengan baik, namun masih terdapatnya nilai akuntabilitas publik lembaga zakat dengan kriteria cukup baik disebabkan oleh masih ada lembaga zakat swasta yang belum memiliki izin dari Baznas dan Kementerian Agama, surat izin pendirian bangunan, ataupun struktur organisasi yang terdaftar di Kementerian Hukum dan Ham.

Kemudian masih ada lembaga zakat yang belum memiliki sarana penunjang dalam keberhasilan menghimpun zakat yang lengkap seperti poster petunjuk pelayanan zakat, himbauan berzakat diruang tunggu atau tempat lainnya, maupun alur kerja pada ruang pelayanan. Masih kurangnya pengetahuan staf atau pegawai mengenai zakat dan perhitungannya, belum memiliki website lembaga dan belum melakukan publikasi laporan menjadi penyebab masih kurangnya akuntabilitas publik lembaga amil zakat.

\subsection{Uji Hipotesis}

\section{Uji Kesesuaian Model}

Uji statistik $\mathrm{F}$ akan menunjukkan apakah variabel akuntansi zakat memiliki pengaruh terhadap variabel akuntabilitas publik. Dengan uji $\mathrm{F}$ akan menjadi dasar dalam menetukan kesimpulan mengenai ada atau tidak adanya pengaruh akuntansi zakat terhadap akuntabilitas publik.

Tabel 4.5.

\section{Hasil Uji F Pengaruh Akuntansi Zakat} Terhadap Akuntabilitas Publik

\begin{tabular}{|l|r|r|r|r|r|}
\hline Model & $\begin{array}{c}\text { Sum of } \\
\text { Squares }\end{array}$ & Df & \multicolumn{1}{|c|}{ Square } & F & Sig. \\
\hline 1 Regression & 9669.799 & 1 & 9669.799 & 79.4 & $.000^{\mathrm{a}}$ \\
Residual & 3411.401 & 28 & 121.836 & & \\
Total & 13081.200 & 29 & & & \\
\hline
\end{tabular}
a. Predictors: (Constant), Akuntansi Zakat
b. Dependent Variable: Akuntabilitas Publik

Tabel 4.5. di atas menunjukkan nilai F yang diperoleh sebesar 79,367. Sedangkan nilai $F$ tabel pada tingkat probabilitas sebesar 0,05 adalah 4,171 dengan probabilitas 0,000 . Karena F hitung lebih besar dari $\mathrm{F}$ tabel dan probabilitas jauh lebih kecil dari 0,05 maka model regresi dapat digunakan untuk memprediksi akuntabilitas publik atau dapat dikatakan bahwa akuntansi zakat berpengaruh terhadap akuntabilitas publik lembaga amil zakat.

\section{Uji Signifikansi t}

Uji t digunakan untuk menjelaskan pengaruh variabel akuntansi zakat terhadap 
Bayu Dharmaraga Alkahfi, Taufiq Taufiq, Inten Meutia, Pengaruh Akuntansi Zakat

variabel akuntabilitas publik secara individual atau parsial.

Tabel 4.6.

Hasil Uji t Pengaruh Akuntansi Zakat

Terhadap Akuntabilitas Publik

\begin{tabular}{|l|r|r|r|r|r|}
\hline \multirow{2}{*}{ Model } & \multicolumn{2}{|c|}{$\begin{array}{l}\text { Unstandardized } \\
\text { Coefficients }\end{array}$} & SC & & \\
\cline { 2 - 6 } & B & $\begin{array}{c}\text { Std. } \\
\text { Error }\end{array}$ & Beta & T & Sig. \\
\hline $1 \quad$ (Constant) & 26.471 & 10.404 & & 2.544 & .017 \\
Akuntansi Zakat & .644 & .072 & .860 & 8.909 & .000 \\
\hline
\end{tabular}

a. Dependent Variable: Akuntabilitas Publik

Dari hasil pada tabel 4.16 diatas dapat diketahui bahwa pengujian hipotesis alternatif (Ha) diterima. Pengujian hipotesis pertama dilakukan dengan cara membandingkan antara hasil dari t-hitung dengan t-tabel. Dari tabel Coefficients diatas diperoleh nilai t-hitung sebesar 8,909. Sementara itu, untuk t-tabel dengan taraf signifikakansi 0,05 diperoleh nilai ttabel $=0,682$. Perbandingan antara keduanya menghasilkan t-hitung > t-tabel yaitu $8,909>0,682$.

Nilai signifikansi t untuk variabel akuntansi zakat adalah 0,000 dan nilai tersebut lebih kecil daripada probabilitas 0,000 lebih kecil dari pada 0,05 . Sehingga dalam pengujian ini menunjukkan bahwa Ha diterima dan Ho ditolak Hal ini berarti bahwa terdapat pengaruh yang positif yang signifikan antara akuntansi zakat terhadap akuntabilitas publik lembaga amil zakat.

Berdasarkan hasil analisis regresi tersebut dapat diketahui persamaan regresi sederhana pada penelitian ini adalah sebagai berikut:

$$
\begin{aligned}
& Y=\alpha+\beta_{1} X_{1}+e \\
& Y=26,471+0,644 X_{1}
\end{aligned}
$$

Persamaan tersebut menunjukkan bahwa konstanta sebesar 26,471, hal ini menunjukkan bahwa apabila variabel akuntansi zakat dianggap nol, maka variabel akuntabilitas publik adalah sebesar 26,471 satuan. Koefisien regresi $\mathrm{X}_{1}$ sebesar 0,644 menunjukkan bahwa setiap kenaikan akuntansi zakat sebesar satu satuan maka akan menaikkan akuntabilitas publik sebesar 0,644. Berdasarkan dari hasil tersebut menunjukkan bahwa arah model regresi ini adalah positif.

\section{Koefisien Determinasi (R Square)}

Koefisien determinasi mengukur seberapa jauh kemampuan model dalam menerangkan variasi variabel dependen. Nilai koefisien determinasi adalah diantara 0 dan 1.

Tabel 4.7.

Koefisien Determinasi

\begin{tabular}{|r|c|r|r|r|r|}
\hline & & $\mathrm{R}$ & Adjusted \\
Model & $\mathrm{R}$ & $\begin{array}{c}\text { Square } \\
\text { R Square }\end{array}$ & $\begin{array}{c}\text { Std. Error } \\
\text { of the } \\
\text { Estimate }\end{array}$ & Wurbin- \\
\hline 1 & $.860^{\mathrm{a}}$ & .739 & .730 & 11.03792 & 2.065 \\
\hline
\end{tabular}

a. Predictors: (Constant), Akuntansi Zakat

b. Dependent Variable: Akuntabilitas Publik

Berdasarkan hasil tabel 4.12 diatas, menunjukkan nilai korelasi (r) bernilai positif sebesar 0,860 dan $\mathrm{R}$ square (R2) yang dihasilkan yaitu sebesar 0,739 atau 
sebesar $73,9 \%$. Hal ini berarti variabel akuntansi zakat mempengaruhi variabel akuntabilitas publik sebesar R2 yaitu sebesar $73,9 \%$, sedangkan sisanya $26,1 \%$ dipengaruhi oleh variabel lain diluar penelitian ini.

\section{Analisis Hasil}

Penelitian ini mendukung hipotesis yang menyatakan bahwa terdapat pengaruh positif antara akuntansi zakat terhadap akuntablitas publik. Hubungan antara akuntansi zakat terhadap akuntablitas publik adalah positif dan signifikan, yang ditunjukkan dengan nilai signifikansi kurang dari level of significant 0,05 atau $0,000<0,050$. Koefisien regresi sebesar 0,644 yang memiliki arah positif yang berarti semakin tinggi akuntansi zakat maka akuntablitas publik lembaga zakat juga semakin tinggi. Koefisien korelasi $\mathrm{r}(\mathrm{x} 1 \mathrm{y})$ sebesar 0,860 dan nilai koefisien determinasi $\mathrm{r} 2(\mathrm{x} 1 \mathrm{y})$ yaitu sebesar 0,739 atau sebesar 73,9\% akuntansi zakat berpengaruh secara positif terhadap akutabilitas publik amil zakat sedangkan sisanya $26,1 \%$ dipengaruhi oleh variabel lain diluar penelitian.

Penelitian ini mendukung beberapa penelitian sebelumnya seperti penelitian Jadzil Baihaqi (2018), Syamsul Hidayat, Nani Rohaeni, Anah Zanatun (2018), Rozy Widhi Bayu Pratama dan Ahmad Roziq (2017), Muh. Fardan Ngoyo, Lince Bulutoding (2016) serta Elvinda Febry
Angraeni, Sifrid S. Pangemanan, Sintje S. Rondonuwu (2016) dimana penelitian mereka bertujuan untuk mengetahui seberapa besar lembaga-lembaga zakat menerapkan akuntansi zakat dan pelaporan keuangan zakat berdasarkan PSAK Nomor 109 Tahun 2010. Berdasarkan hasil penelitian ini peneliti menyumbangkan buah pikir bahwa akuntansi zakat atau pelaporan keuangan lembaga zakat memiliki peran yang sangat penting dalam meningkatkan akuntabilitas publik lembaga amil zakat.

Penelitian ini juga melanjutkan penelitian sebelumnya yang dilakukan oleh Adnan (2015), Hidayat, Rohaeni \& Zanatun (2018) tentang transparansi laporan keuangan lembaga zakat yang baik sesuai dengan PSAK Nomor 109, Penelitian ini menjelaskan penelitian Rahman (2015), Yusuf dan Derus (2013) bahwa beberapa faktor yang mempengaruhi keberhasilan zakat salah satunya adalah kepercayaan (trust). Berdasarkan hasil penelitian ini menemukan bahwa akuntansi zakat memiliki pengaruh positif terhadap akuntabilitas publik lembaga zakat, yang artinya semakin tinggi penerapan akuntansi zakat maka semakin tinggi pula akuntabilitas publik. Akuntabilitas publik berbanding lurus dengan kepercayaan muzzaki. 
Hasil penelitian ini sejalan dengan penelitian Nikmatuniayah, Marliyati, Lilis Mardiana (2017) yang menjelaskan bahwa kualitas informasi akuntansi dan transparansi penerimaan zakat berpengaruh terhadap penerimaan dana zakat. Pada penelitian ini peneliti menemukan bahwa akuntabilitas publik lembaga zakat $73,9 \%$ dipengaruhi oleh akuntansi zakat. Penelitian ini sesuai dengan teori yang digunakan, dimana Syariah Enterprise Theory menjelaskan bahwa konsep SET memiliki rasa tanggungjawab kepada stakeholders yang luas meliput Allah SWT, manusia maupun alam dan tidak hanya peduli kepada kepentingan suatu individu. Sehingga pelaporan keuangan bukan hanya ditujukan kepada atasan namun kepada masyarakat umum dan juga kepada Allah SWT, dengan laporan yang ditujukan kepada masyarakat akan membuat kepercayaan masyarakat kepada lembaga zakat meningkat yang pada akhirnya akan sangat berpengaruh terhadap keberhasilan mengumpulkan zakat, sehingga tujuan akhir zakat untuk kemaslahatan umat dapat terwujud.

\section{Simpulan}

Hasil penelitian ini menunjukkan adanya pengaruh positif yang signifikan antara akuntansi zakat dan akuntabilitas publik lembaga amil zakat. Nilai signifikansi untuk variabel akuntansi zakat adalah 0,000 lebih kecil daripada 0,05. Hasil tersebut menunjukkan bahwa Ho ditolak, artinya terdapat pengaruh positif yang signifikan antara akuntansi zakat terhadap akuntabilitas publik.

\section{Daftar Pustaka}

Abdullah, N., Mat Derus, A., \& AlMalkawi, H.-A. N. (2015). The effectiveness of zakat in alleviating poverty and inequalities. Humanomics, 31(3), 314-329. https://doi.org/10.1108/H-02-20140016

Abu-tapanjeh, A. M. (2009). Corporate governance from the Islamic perspective: A comparative analysis with OECD principles. 20, 556-567. https://doi.org/10.1016/j.cpa.2007.12.0 04

Adnan, M. A. (2015). Journal of Islamic Accounting and Business Research. Journal of Islamic Accounting and Business Research Shochrul Rohmatul Ajija Humanomics Iss Thomas J. Case, Brian H. Kleiner Work Study, 64(3), 244-267. Retrieved from http://dx.doi.org/10.1108/JIABR-062013-

0017\%5Cnhttp://dx.doi.org/10.1108/E UM0000000002698

Akbar, R., Pilcher, R., \& Perrin, B. (2012). Performance measurement in Indonesia: the case of local government.

https://doi.org/10.1108/011405812112 83878

Alkahfi, A. (2018). Peran Badan Amil Zakat Nasional Provinsi Sumatera Selatan Dalam Rangka Penghimpunan dan Pendistribusian Dana Amil Zakat Sebagai Upaya Meningkatkan Kesejahteraan Masyarakat Kurang 
Mampu di Kota Palembang (Vol. 53). https://doi.org/10.1017/CBO97811074 15324.004

Elvinda. (2016). ISSN 2303-1174 E.F. Angraeni., S.S. Pangemanan., S. S. Rondonuwu.Penerapan Akuntanssi Zakat ..... 4(4), 1191-1199.

Hidayat, S., Rohaeni, N., \& Zanatun, A. (2018). Implementasi Pernyataan Standar Akuntansi Keuangan 109 Pada Yayasan Rumah Yatim Arrohman: Identifikasi Faktor Pendukung. Jati: Jurnal Akuntansi Terapan Indonesia, 1(1), 17-26. https://doi.org/10.18196/jati.010102

Hughes, O. E. (2003). Public Management and Administration: An Introduction (3rd ed.). Macmillan Education UK.

Ikatan Akuntan Indonesia. (2008). PSAK No. 109 Tentang Akuntansi Zakat dan Infaq/Sedekah. Ikatan Akuntan Indonesia (IAI).

Keutamaan, P., Dan, O., \& Publik, A. (2018). Peran keutamaan organisasi dan akuntabilitas publik dalam memengaruhi kinerja sektor publik di organisasi perangkat daerah propinsi banten. 11(2).

Kudus, K. (2018). Diskursus Akuntansi Zakat: Evaluasi Praktis Laporan Keuangan Lazisnu Kabupaten Kudus. 1, 1-12.

Lalolo Krina, L. (2003). Indikator \& Alat Ukur Prinsip Akuntabilitas, Transparansi \& Partisipasi. Badan Perencanaan Pembangunan Nasional.

Mahmudi. (2013). Manajemen Kinerja Sektor Publik. Yogyakarta: Sekolah Tinggi Ilmu Manajemen YKPN.

Mardiasmo. (2004). Akuntansi Sektor Publik, Jurnal Akuntansi Pemerintahan (1st ed.). Yogyakarta: Andi.
Meutia, I. (2010). Shariah Enterprise Theory Sebagai Dasar Pengungkapan Tanggungjawab Sosial Untuk Bank Syariah. Universitas Brawijaya.

Mursyidi. (2003). Akuntansi Zakat Kontemporer (Mursyidi, Ed.). Bandung: PT Remaja Rosdakarya.

PIRAC. (2007). Meningkat, Kesadaran dan Kapasitas Masyarakat dalam Berzakat (H. Abidin \& Kurniawati, Eds.). Public Interest Research \& Advocacy Public.

Rahman, T. (2015). Akuntansi Zakat, Infak dan Sedekah (PSAK 109): Upaya Peningkatan Transparansi dan Akuntabilitas Organisasi Pengelola Zakat (OPZ). Jurnal Muqtasid, 6(109), 141-164. https://doi.org/10. 1007/s00410-004-0612-0

Rasul, S. (2003). Pengintegrasian Sistem Akuntabilitas Kinerja dan Anggaran dalam Perspektif UU NO. 17/2003 Tentang Keuangan Negara. Jakarta: PNRI.

Ritonga, P. (2017). Analisis Akuntansi Zakat Berdasarkan PSAK No. 109 Pada Badan Amil Zakat Nasional (BAZNAS) Sumatera Utara. KITABAH, (109).

Roziq, R. W. B. dan A. (2017). Implementasi Akuntansi Zakat Infaq dan Shadaqah Berdasarkan PSAK 109 Implementation of Accounting Zakat, Infaq and Shadaqah Based on PSAK 109. Ekonomi Bisnis Dan Akuntansi, IV(109), 35-39.

Sugiyono. (2010). Metode Penelitian dan Pengembangan. Alfabeta.

Triyuwono, I. (2006). Perspektif, Metodologi dan Teori Akuntansi Syari'ah (1st ed., Vol. 1). Jakarta: Radjawali Press.

Turner, M., \& Hulme, D. (1997). Governance, administration and 
Bayu Dharmaraga Alkahfi, Taufiq Taufiq, Inten Meutia, Pengaruh Akuntansi Zakat

development: making the state work. Basingstoke: Macmillan Press.

Yusrianti, H., \& Safitri, R. H. (2015). Implementasi Sistem Akuntabilitas Kinerja Instansi Pemerintah (Sakip) Pada Satuan Kerja Perangkat Daerah (Skpd) Di Lingkungan Pemerintah Pemerintah Kota Palembang. Jurnal Manajemen \& Bisnis Sriwijaya Vol., 13(4), 399-404.

Yusuf, M. B. O., \& Derus, A. M. (2013). Measurement model of corporate zakat collection in Malaysia: A test of diffusion of innovation theory. Humanomics, 29(1), 61-74. https://doi.org/10.1108/082886613112 99321 